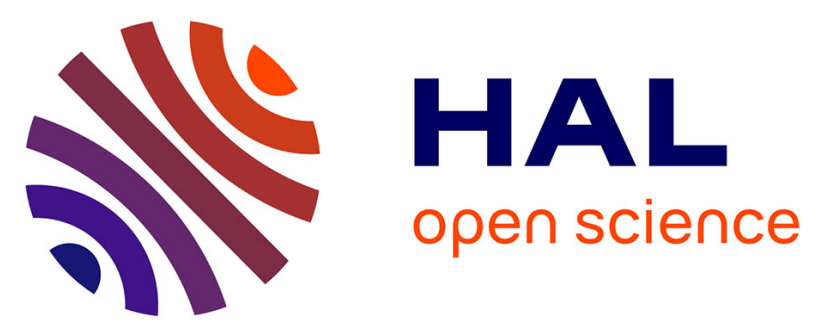

\title{
Terpenoid-derived conjugated dienes with exo-methylene and 6 membered ring: high cationic reactivity, regioselective living cationic polymerization, and random and block copolymerization with vinyl ethers
}

\author{
Takenori Nishida, Kotaro Satoh, Masazumi Tamura, Yingai Li, Keiichi \\ Tomishige, Sylvain Caillol, Vincent Ladmiral, Marylène Vayer, Frédéric \\ Mahut, Christophe Sinturel, et al.
}

\section{- To cite this version:}

Takenori Nishida, Kotaro Satoh, Masazumi Tamura, Yingai Li, Keiichi Tomishige, et al.. Terpenoidderived conjugated dienes with exo-methylene and 6membered ring: high cationic reactivity, regioselective living cationic polymerization, and random and block copolymerization with vinyl ethers. Polymer Chemistry, 2021, 12 (9), pp.1186-1198. 10.1039/d1py00035g · hal-03163687

\author{
HAL Id: hal-03163687 \\ https://hal.science/hal-03163687
}

Submitted on 9 Mar 2021

HAL is a multi-disciplinary open access archive for the deposit and dissemination of scientific research documents, whether they are published or not. The documents may come from teaching and research institutions in France or abroad, or from public or private research centers.
L'archive ouverte pluridisciplinaire HAL, est destinée au dépôt et à la diffusion de documents scientifiques de niveau recherche, publiés ou non, émanant des établissements d'enseignement et de recherche français ou étrangers, des laboratoires publics ou privés. 


\title{
Terpenoid-derived conjugated dienes with exo-methylene and 6- membered ring: high cationic reactivity, regioselective living cationic polymerization, and random and block copolymerization with vinyl ethers
}

\author{
Takenori Nishida, ${ }^{a}$ Kotaro Satoh, ${ }^{a, b}$ Masazumi Tamura, ${ }^{*} c$ Yingai Li, ${ }^{d}$ Keiichi Tomishige, ${ }^{d}$ Sylvain \\ Caillol, ${ }^{e}$ Vincent Ladmiral, ${ }^{e}$ Marylène Vayer, ${ }^{f}$ Frédéric Mahut, ${ }^{f}$ Christophe Sinturel ${ }^{* f}$ and Masami \\ Kamigaito $^{* a}$
}

A series of biobased conjugated dienes with exo-methylene and a 6-membered ring was prepared from naturally abundant terpenoids bearing an $\alpha, \beta$-unsaturated carbonyl group, such as verbenone, piperitone, or carvone, and cationically polymerized to form novel biobased cycloolefin polymers with characteristic structures originating from natural products. The obtained exo-methylene-conjugated dienes showed high cationic polymerizability comparable to that of vinyl ethers despite the absence of electron-donating heteroatoms. The polymerization proceeded via regioselective 1,4-conjugated addition by initiating systems effective for living cationic polymerization of vinyl ethers, resulting in well-defined polymers with controlled molecular weights and substituted cyclohexenyl rings in the main chain. These polymers showed high glass transition temperatures $\left(T_{\mathrm{g}}\right)$ ranging from 110 to $160{ }^{\circ} \mathrm{C}$ depending on the substituents. The hydrogenation of the mainchain cyclohexenyl ring resulted in novel biobased cycloolefin polymers with good thermal stability. The reactivity of the exo-methylene-conjugated diene monomers was evaluated by living cationic copolymerizations with a series of vinyl ethers with different reactivities, i.e., isopropyl, isobutyl, and 2-chloroethyl vinyl ether. In particular, the dienes possessing a methyl group at the 4-position, which can generate a conjugated tertiary cation, were more reactive than a representative vinyl ether with an isobutyl substituent. The sequence distribution of the copolymers varied from statistically random to tapered block structures depending on the monomer reactivities. Block copolymerizations of the dienes and vinyl ethers using the same initiating system for sequential monomer addition resulted in well-defined block copolymers bearing high $\left(>100^{\circ} \mathrm{C}\right)$ and low $\left(\sim 0^{\circ} \mathrm{C}\right) T_{\mathrm{g}}$ segments, of which microphase separation was confirmed by atomic force microscopy of the thin film.

\section{Introduction}

In nature, a series of natural compounds are produced via biological synthetic pathways consisting of sequential transformation reactions in plants, in which terpenoids are among the most versatile in the chemical structures in terms of linear and cyclic structures, stereostructures including chirality, and functional groups, such as olefins, ketones, and alcohols. $^{1-4}$ These natural compounds with specific chemical structures are not only necessary in their biological activities as attractant or repellent substances but also useful in human activities, functioning as natural oils, flavors, fragrances, and key building blocks for biologically active compounds in pharmaceutical and biotechnology industries.

In polymer industries, renewable resources originating from natural products are now important to replace the petrochemical feedstock for synthetic polymers in view of recent environmental issues related to global warming and accumulating plastic wastes. ${ }^{5-13}$ In addition to renewability, unique biobased monomers derived from natural compounds can provide novel polymer properties and/or functions originating from their unique natural structures, which are different from the simple chemical structures of commercially available petroleum-based monomers.

Terpenoids often possess unsaturated $\mathrm{C}=\mathrm{C}$ bonds because they are biosynthetically derived from isopentenyl pyrophosphate via condensation reactions followed by a sequence of enzymatic transformation reactions such as cyclization, isomerization, and oxidation. Therefore, many unsaturated terpenoids with a variety of isomeric structures are seen in various plants, and some of them are abundant. Terpenoids would be attractive as starting materials for biobased vinyl monomers with novel structures, which could result in unique reactivities in the polymerizations and characteristic properties and functions of the resulting polymers. ${ }^{14-17}$ Terpenes occupy a very original place among renewable resources because they are aliphatic and contain no or few heteroatoms, unlike plant oil and sugar derivatives. Therefore, terpenes make it possible to obtain structures that resemble certain petrosourced polymers in relatively few steps.

From this viewpoint, we have been investigating the polymerization of terpene-derived vinyl compounds to pursue the unique reactivity of novel biobased monomers and characteristic properties of the resulting biobased polymers. ${ }^{18-}$ ${ }^{26}$ As a typical result, we have found that naturally abundant $\beta$ pinene ( $\beta$-Pin), which has an exo-methylene moiety and 4 - and 6 -membered fused ring, is readily polymerized by cationic

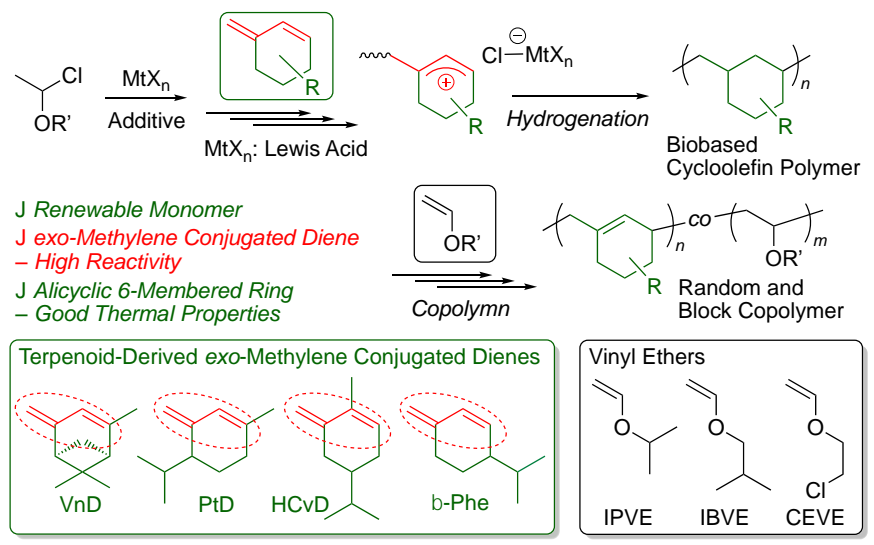

Scheme 1. Cationic polymerization of terpenoid-derived exo-methylene 6-membered conjugated dienes and copolymerization with vinyl ethers. 
polymerization under optimized conditions to give highmolecular-weight polymer with a characteristic cyclohexenyl ring in the main chain by ring-opening of the 4-membered ring. ${ }^{18,19}$ The subsequent hydrogenation of the unsaturated unit results in a novel cycloolefin polymer (COP) composed of alternating 1,4-cyclohexane and isobutylene units, and this polymer shows various excellent properties such as high transparency, low birefringence, high glass transition temperature $\left(T_{\mathrm{g}}\right)$, moisture insensitivity, and low density, originating from the unique biobased structures. We have also synthesized a similar biobased COP from $\beta$-phellandrene ( $\beta$ Phe), which is another terpene having an exo-methylene-conjugated diene with a 6-membered ring, via cationic polymerization and subsequent hydrogenation. ${ }^{27}$

More recently, we focused on another abundant terpenoid, carvone (a cyclic $\alpha, \beta$-unsaturated carbonyl compound), because its conjugated carbonyl group could be transformed into a similar exo-methyleneconjugated diene, resulting in a novel biobased vinyl monomer. ${ }^{28}$ Indeed, we synthesized two biobased exomethylene-conjugated dienes (CVD: carvone-derived diene, HCvD: hydrogenated carvone-derived diene) (Scheme 1), which both showed relatively high reactivity in cationic polymerization. Although CVD induced concurrent cross-linking reactions due to the additional pendant olefin, HCVD underwent 1,4regioselective and stereospecific living cationic polymerization to result in a novel biobased COP with a high $T_{\mathrm{g}}$ after hydrogenation. For the cationic polymerization of another biobased exo-methylene-conjugated diene, Hillmyer et al. reported another biobased exo-methylene-conjugated diene with a 5-membered ring (3-methylenecyclopentene), which was prepared via a ring-closing metathesis reaction of myrcene and was cationically polymerized, resulting in a semicrystalline polymer. ${ }^{29}$ Thus, exo-methylene-conjugated dienes are promising monomers in cationic polymerization that result in attractive polymers with interesting properties.

In this study, we focused on the cationic polymerization of a series of exo-methylene-conjugated dienes that are prepared from other naturally occurring $\alpha, \beta$-unsaturated carbonyl compounds with 6-membered rings: verbenone and piperitone. Verbenone is a main constituent of Spanish verbena and rosemary oils obtained from Verbena triphylla and Rosmarinus officinalis and possesses 4- and 6-membered fused rings similar to one of the most abundant terpenes, $\alpha$ pinene. ${ }^{1-4,30}$ Indeed, another route to verbenone is chemical or biological oxidation of $\alpha$-pinene. ${ }^{31-36}$ Piperitone is a dominant component of essential oils obtained from a family of Eucalyptus dives, Mentha, and Cymbopogon and has a structure similar to hydrogenated carvone in terms of substituents, methyl and isopropyl groups on the cyclohexene ring, whereas the substituted positions are different. ${ }^{1-4,37,38}$ Piperitone is also obtained by chemical and biological oxidation of limonene and $p$-menthene. ${ }^{39,40}$ Both these $\alpha, \beta$ unsaturated carbonyl compounds are used in flavor, fragrance, and medicinal industries. We recently reported the synthesis of verbenone- and piperitone-derived conjugated dienes with exo-methylene and 6-membered rings, i.e., $\mathrm{VnD}$ and $\mathrm{PtD}$, respectively, and radical homo- and copolymerizations, although their radical homopolymerizabilities were very low. ${ }^{41}$ Matsumoto and Yamamoto previously reported radical copolymerization of these dienes with maleimide derivatives, ${ }^{42}$

Table 1 Conventional cationic polymerization of (-)-VnD, PtD, and ( \pm )- $-\mathrm{HCvD}^{a}$

\begin{tabular}{|c|c|c|c|c|c|c|c|}
\hline Entry & Monom & Lewis acid & Time & Conv. $(\%)^{b}$ & $M_{\mathrm{n}}{ }^{c}$ & $M_{\mathrm{w}} / M_{\mathrm{n}}{ }^{c}$ & $1,4-/ 1,2^{d}$ \\
\hline 1 & VnD & $\mathrm{EtAlCl}_{2}$ & $10 \mathrm{sec}$ & $>99$ & 43800 & 1.25 & $>99 / 0$ \\
\hline 2 & VnD & $\mathrm{TiCl}_{4}$ & $10 \mathrm{sec}$ & $>99$ & 26200 & 1.46 & $>99 / 0$ \\
\hline 3 & VnD & $\mathrm{BF}_{3} \cdot \mathrm{OEt}_{2}$ & $10 \mathrm{sec}$ & 0 & n.d. ${ }^{e}$ & n.d. ${ }^{e}$ & n.d. ${ }^{e}$ \\
\hline 4 & VnD & $\mathrm{BF}_{3} \cdot \mathrm{OEt}_{2}$ & $12 \mathrm{~h}$ & $>99$ & 36600 & 1.81 & $>99 / 0$ \\
\hline 5 & VnD & $\mathrm{SnCl}_{4}$ & $10 \mathrm{sec}$ & 93 & 53300 & 1.73 & $>99 / 0$ \\
\hline 6 & PtD & $\mathrm{SnCl}_{4}$ & $10 \mathrm{sec}$ & 63 & $78100^{f}$ & 4.58 & n.d. ${ }^{e}$ \\
\hline 7 & PtD & $\mathrm{SnCl}_{4}$ & $30 \mathrm{sec}$ & $>99$ & $67300^{f}$ & 4.18 & n.d. ${ }^{e}$ \\
\hline 8 & $( \pm)-H C v D$ & $\mathrm{SnCl}_{4}$ & $10 \mathrm{sec}$ & $>99$ & $366700^{f}$ & 2.01 & n.d. ${ }^{e}$ \\
\hline \multicolumn{8}{|c|}{$\begin{array}{l}{ }^{a} \text { Polymerization conditions: }[\mathrm{M}]_{0} /[\text { Lewis acid }]_{0}= \\
100 / 5.0 \mathrm{mM} \text { in toluene } / \mathrm{CH}_{2} \mathrm{Cl}_{2}(50 / 50 \text { vol\%) at - } \\
78{ }^{\circ} \mathrm{C} .{ }^{b} \text { Determined by }{ }^{1} \mathrm{H} \text { NMR of reaction } \\
\text { mixture. }{ }^{c} \text { Determined by SEC. }{ }^{d} \text { Determined by }{ }^{1} \mathrm{H} \\
\text { NMR of the obtained polymers. }{ }^{e} \text { Not }\end{array}$} \\
\hline
\end{tabular}

but there have been no studies on their cationic polymerizations or properties of homopolymers. Herein, we investigated the cationic polymerizations of a series of biobased conjugated dienes with exo-methylene and 6membered rings to clarify the reactivity of the monomers as well as the properties of the polymers originating from unique biobased structures. In addition, random and block cationic copolymerizations with vinyl ethers (VEs) were examined for the synthesis of unprecedented well-defined copolymers using specific reactivities and characteristic structures.

\section{Results and discussion}

\section{Synthesis of monomers}

Verbenone (enantiomeric pure (-)-form) and piperitone (mixture of enantiomers, predominantly $(R)-(-)$-form) were converted into exo-methylene-conjugated dienes, $(-)-\mathrm{VnD}$ (purity: $>99 \%,[\alpha]_{D}=-43.5^{\circ}$ ) and PtD (purity: 95\%, $[\alpha]_{D}=$ $\left.+15.7^{\circ}\right)$, respectively, by the Wittig reaction as reported previously. ${ }^{41,42}$ Racemic $( \pm)$-HCvD $\left([\alpha]_{D}=-1.9^{\circ}\right)$ was prepared by mixing equimolar amounts of (+)- and (-)-HCvD, which were synthesized via selective hydrogenation of the pendant olefins in (+)- and (-)-carvone, respectively, followed by the Wittig reaction as reported. ${ }^{28}$ These biobased compounds are all exomethylene-conjugated dienes with a 6-membered cyclohexenyl ring, whereas the position of the methyl group as 
the substituent reaction is different (3- (HCVD) or 4-position ( $\mathrm{VnD}$ and $\mathrm{PtD}$ ) to the exo-methylene carbon in the conjugated diene). The presence or position of a methyl group substituted on the diene could affect the reactivity in cationic polymerization, as will be discussed later.

\section{Conventional cationic polymerization of (-)-VnD, PtD, and ( \pm )- HCvD}

To evaluate the cationic reactivity of a series of exo-methylene 6-membered ring-conjugated dienes, the polymerizations were investigated with various conventional Lewis acid catalysts (Table 1 and Fig. S1).

The cationic homopolymerization of $(-)-\mathrm{VnD}$ proceeded quantitatively with all Lewis acids, including $\mathrm{EtAlCl}_{2}, \mathrm{TiCl}_{4}$, $\mathrm{BF}_{3} \cdot \mathrm{OEt}_{2}$, and $\mathrm{SnCl}_{4}$, in a 1:1 mixture of toluene and $\mathrm{CH}_{2} \mathrm{Cl}_{2}$ at $78{ }^{\circ} \mathrm{C}$ and resulted in homopolymers with relatively high molecular weights $\left(M_{\mathrm{n}}>25000\right)$, unlike its radical homopolymerization, which yielded only low molecular weight oligomers $\left(M_{\mathrm{n}}<1000\right){ }^{41}$ In addition, the cationic polymerizations were almost instantaneous except for $\mathrm{BF}_{3} \cdot \mathrm{OEt}_{2}$, indicating that the reactivity of $(-)-\mathrm{VnD}$ is extremely high despite the absence of electron-donating heteroatoms such as the oxygen in VEs. The poly $((-)-V n D)$ obtained from all Lewis acid catalysts showed similar ${ }^{1} \mathrm{H}$ NMR spectra (Fig. S2), where the peaks of the methyl protons $(c)$ at the 4-position shifted upfield from 1.7-1.8 ppm to $0.8-1.0 \mathrm{ppm}$ after polymerization, suggesting that the carbon at the 4-position was changed from unsaturated to saturated via 1,4-conjugated addition. Furthermore, the peak intensity ratio of the olefin proton $(b)$ to the methyl proton $(c)$ was exactly $1: 3$, indicating that the regioselective 1,4-conjugated addition polymerization proceeded regardless of the catalyst. In particular, other protons formed via the 1,2-addition and ring-opening of the 4membered ring in $\mathrm{VnD}$ were not observed, indicating again that the 1,4-conjugated addition selectively occurred due to the stable tertiary allylic propagating cation.

The cationic polymerizations of PtD and $( \pm)$-HCVD were also examined using $\mathrm{SnCl}_{4}$, which generated the highest-molecularweight polymer from (-)-VnD (Table 1). Both PtD and ( \pm )-HCvD were consumed rapidly and quantitatively, although their relative reactivities could not be compared due to the very fast reactions. The polymers resulting from the cationic polymerization of PtD and ( \pm )-HCvD had higher molecular weights $\left(M_{\mathrm{n}} \sim 78000\right.$ and 360000, respectively) than those obtained by radical homopolymerizations. ${ }^{41}$ In addition, these $M_{n}$ values are likely underestimated, as they correspond only to the soluble fractions of the polymers in $\mathrm{CHCl}_{3}$ and tetrahydrofuran (THF) (Fig. S1).

All these results indicate that these exo-methylene 6membe

red

ring-

conjuga

ted

dienes

have

extreme

ly high reactivity in cationic polymerization as hydrocarbon monomers without heteroatoms and produce high-molecular-weight polymers with conventional Lewis acid catalysts.

\section{Living cationic polymerization of exo-methylene-conjugated dienes}

The living cationic polymerization of $(-)-\mathrm{VnD}$ and PtD was then examined using a typical initiating system consisting of a hydrogen chloride adduct (1) of 2-chloroethyl vinyl ether (CEVE) as an initiator, $\mathrm{SnCl}_{4}$ as an activator, and $n \mathrm{Bu}_{4} \mathrm{NCl}$ as an added salt, which is generally effective for the living cationic
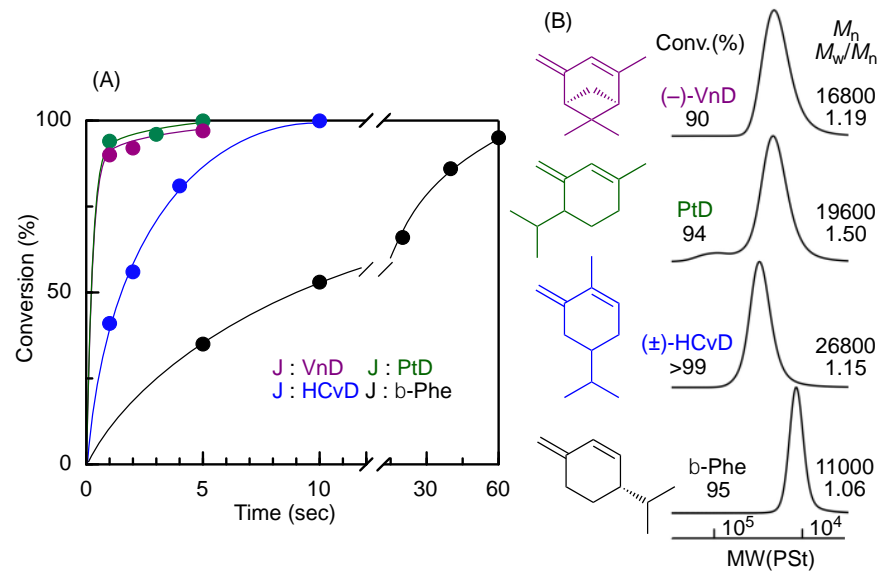

Fig. 1. Time-conversion $(A)$ and SEC curves $(B)$ obtained in cationic polymerization of ()-VnD, PtD, ( \pm )-HCVD, and $\beta$-Phe: $[\mathrm{M}]_{0} /[1]_{0} /\left[\mathrm{SnCl}_{4}\right]_{0} /\left[n \mathrm{Bu}_{4} \mathrm{NCl}\right]_{0}=100 / 1.0 / 5.0 / 4.0$ in toluene $/ \mathrm{CH}_{2} \mathrm{Cl}_{2}\left(50 / 50\right.$ vol\%) at $-78^{\circ} \mathrm{C}$.

polymerization of various cationically polymerizable vinyl monomers such as VEs. ${ }^{28,43,44}$ Fig. $1 \mathrm{~A}$ shows time-conversion curves for the cationic polymerization of $(-)-\mathrm{VnD}$ and $\mathrm{PtD}$ in a 1:1 mixture of toluene and $\mathrm{CH}_{2} \mathrm{Cl}_{2}$ at $-78{ }^{\circ} \mathrm{C}$ and those for the other exo-methylene conjugated dienes with similar structures, $( \pm)$-HCvD and $\beta$-Phe, under the same conditions. Both (-)-VnD and PtD were polymerized much faster than ( \pm )HCVD and $\beta$-Phe and were nearly completely consumed within $5 \mathrm{sec}$, resulting in polymers that were soluble in various common organic solvents such as hexane, $\mathrm{CHCl}_{3}$, and THF. Thus, (-)-VnD and PtD possess higher reactivities than ( \pm )HCVD and $\beta$-Phe in cationic polymerization. Despite the very fast polymerizations, the size-exclusion chromatography (SEC) curves of the obtained poly $((-)-\mathrm{VnD})$ and poly(PtD) showed relatively narrow molecular weight distributions (MWDs) for the main peaks (Fig. 1B), suggesting that the polymerizations proceeded in a living or controlled fashion.

The reactivity of a series of biobased conjugated dienes with exo-methylene and 6-membered rings thus increased in the following order: $\beta$-Phe $<\mathrm{HCVD}<\mathrm{PtD} \sim \mathrm{VnD}$ (Fig. 1A). This order is reasonable when these monomers are classified into 
three groups, which bear a methyl group at the 4- (VnD and PtD) and 3-positions (HCvD) and no methyl group ( $\beta$-Phe). The electron-donating methyl group increases the electron density of the conjugated diene and thus increases the reactivity of the monomers in the cationic polymerization. Furthermore, in $\mathrm{VnD}$ and PtD, the methyl group at the 4-position results in a more stable tertiary cation via regioselective 1,4-conjugated addition. The MWDs were also affected by the monomer structures or the polymerization rates. As usual, faster polymerization resulted in a broader MWD, which can be attributed to the fast propagation compared with interconversion between the dormant and growing cationic species. However, the effects of steric factors on monomer reactivity should also be considered and are under investigation by preparing and polymerizing model compounds (exo-methylene- and 6-membered ring-conjugated dienes substituted with only one methyl group).

To further confirm the molecular weight control using the $\mathrm{R}-\mathrm{Cl} / \mathrm{SnCl}_{4} / n \mathrm{Bu}_{4} \mathrm{NCl}$ initiating system, the feed ratio of monomer to initiator was varied by changing the concentration of initiator while keeping the concentration of the monomer constant (Fig. 2). Herein, the hydrogen chloride adduct (2) of isobutyl vinyl ether (IBVE) was chosen as an initiator to ensure faster initiation. The polymerization was instantaneously completed in all cases $\left(\left[\mathrm{M}_{0}\right] /[2]_{0}=25,50,100\right)$ to yield polymers with narrow MWDs and controlled molecular weights, indicating that the polymerization proceeded in a living or controlled fashion. Although the $M_{n}(S E C)$ values based on calibration by polystyrene were higher than the calculated values, the $M_{n}$ (MALLS) measured by multiangle laser light scattering (MALLS) agreed well with the calculated values assuming that one molecule of $\mathbf{2}$ generates one polymer chain. For PtD, a small shoulder in the high-molecular-weight region was observed and could be attributed to aggregation of the polymers because the intensity of this shoulder decreased after heating the sample THF solution at $60^{\circ} \mathrm{C}$ (Fig. S3).

The structures of the polymers obtained from (-)-VnD and PtD were analyzed by ${ }^{1} \mathrm{H}$ and ${ }^{13} \mathrm{C}$ NMR and additionally using COSY, DEPT, and HMQC techniques (Fig. 3 and S4-S7). As in the case of conventional cationic polymerization of $(-)-V n D$, polymerizations of both monomers proceeded via regioselective 1,4-conjugated addition. A similar 1,4conjugated addition polymerization was reported for HCVD and $\beta$-Phe. ${ }^{27,28}$ Furthermore, the $M_{n}(\mathrm{NMR})$ values, which were measured from peak intensity ratios of main chain $(b)$ to IBVE unit $\left(\alpha_{2}\right)$ originating from the initiator, were close to the calculated values $\left(M_{\mathrm{n}}(\mathrm{calcd})\right)$ assuming that one initiator generates one polymer chain. These results indicate that 2 efficiently initiates the regioselective living cationic polymerizations of $(-)-\mathrm{VnD}$ and $\mathrm{PtD}$ in the presence of appropriate amounts of $\mathrm{SnCl}_{4}$ and $n \mathrm{Bu}_{4} \mathrm{NCl}$.

The other initiating systems, which are effective for living cationic polymerizations of $\mathrm{VEs},{ }^{44}$ were also employed for (-)$\mathrm{VnD}, \mathrm{PtD}$, and ( \pm )-HCVD (Table S1). The initiating system with a weaker Lewis acid such as $\mathrm{ZnCl}_{2}$ was also effective for controlling the cationic polymerization of $(-)-\mathrm{VnD}$ and resulted in polymers with controlled molecular weights and narrow MWDs $\left(M_{\mathrm{w}} / M_{\mathrm{n}} \sim 1.15\right)$ in toluene (Fig. S8). Although the SEC trace of the polymers obtained at high conversion (>99\%) showed a small shoulder at a molecular weight, which was almost double the shoulder of the main peak. This shoulder could be attributed to the coupling products between the growing cationic species and the exo-methylene moiety, which was formed via $\beta$-proton elimination from the methyl group at the $\omega$-terminus of another polymer chain. The formation of an exo-methylene moiety at the $\omega$-terminus was suggested by the ${ }^{1} \mathrm{H}$ NMR spectrum of the polymer obtained with $\mathrm{ZnCl}_{2}$ (Fig. S9). The $\mathrm{ZnCl}_{2}$-based system was not suitable for inducing the cationic polymerization of PtD and ( \pm )-HCVD, as indicated by the slower polymerizations and broader MWDs of the resulting polymers (Table S1). The $\mathrm{R}-\mathrm{Cl} / \mathrm{SnCl}_{4} / n \mathrm{Bu}_{4} \mathrm{NCl}$ initiating system, in which the molar ratio of $\mathrm{SnCl}_{4} / n \mathrm{Bu}_{4} \mathrm{NCl}$ was slightly higher than 1, was most effective for controlling the cationic polymerization of a series of biobased conjugated dienes with exo-methylene and 6-membered rings.
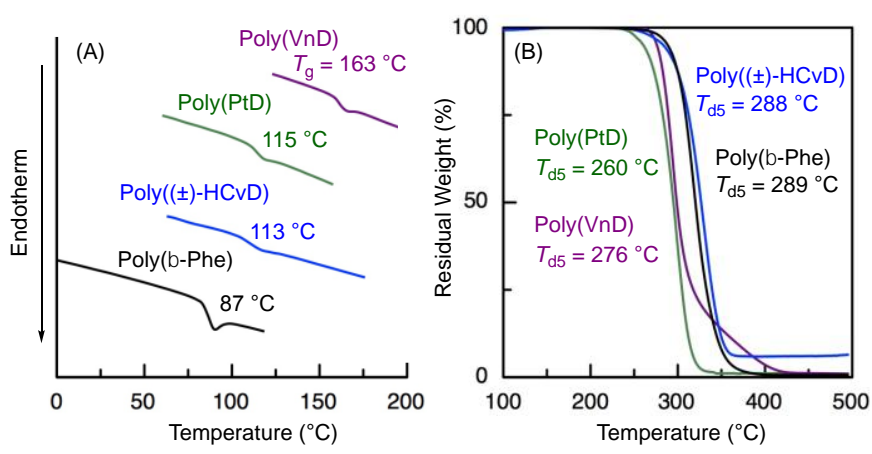

Fig. 4. Differential scanning calorimetry (DSC) (A) and thermogravimetric analysis (TGA) (B) curves of poly $((-)-V n D)\left(M_{n}=17000\right)$, poly $($ PtD $)\left(M_{n}=20000\right)$, poly $(( \pm)$ $\operatorname{HCvD})\left(M_{\mathrm{n}}=26500\right)$, and poly $(\beta-\mathrm{Phe})\left(M_{\mathrm{n}}=90000\right)$.

\section{Thermal and optical properties of polymers}

The thermal properties of poly $((-)-\mathrm{VnD})$ and poly(PtD) were evaluated by differential scanning calorimetry (DSC) and thermogravimetric analysis (TGA) and were compared with those of poly $(( \pm)-\mathrm{HCV} D)\left(M_{\mathrm{n}}(\mathrm{SEC})=26500\right)$ and $\operatorname{poly}(\beta-\mathrm{Phe})$ $\left(M_{\mathrm{n}}(\mathrm{SEC})=90000\right)$. The DSC curves of poly $((-)-\mathrm{VnD})\left(M_{\mathrm{n}}(\mathrm{SEC})=\right.$
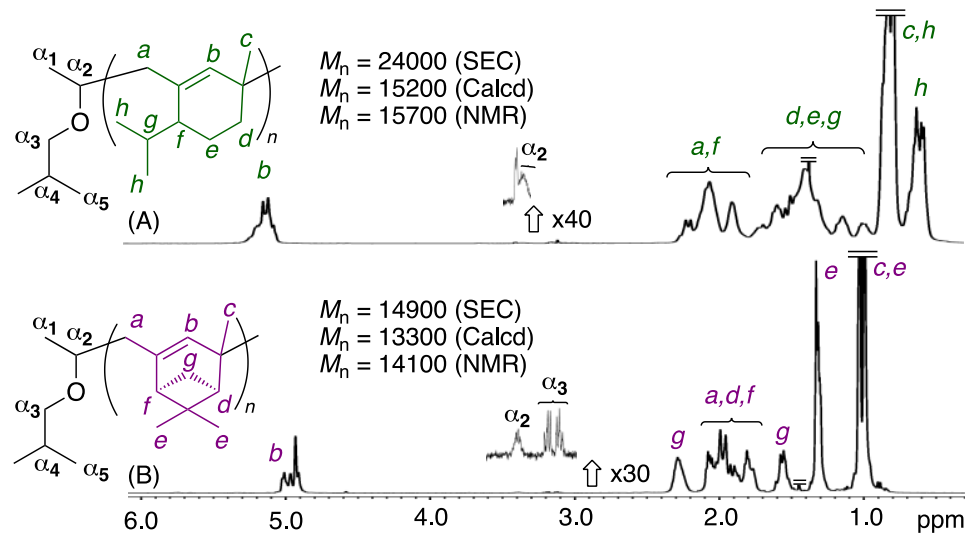

Fig. 3. ${ }^{1} \mathrm{H}$ and ${ }^{13} \mathrm{C}$ NMR spectra (in $\mathrm{CDCl}_{3}$ at $55{ }^{\circ} \mathrm{C}$ ) of poly $(\mathrm{PtD})$ and poly $\left((-)-\mathrm{VnD}\right.$ ) obtained in cationic polymerization: $[\mathrm{M}]_{0} /[2]_{0} /[\mathrm{SnCl}]_{0} /\left[n B \mathrm{Bu}_{4} \mathrm{NCl}\right]_{0}=100 / 1.0 / 5.0 / 4.0 \mathrm{mM}$ in toluene $/ \mathrm{CH}_{2} \mathrm{Cl}_{2}\left(50 / 50\right.$ vol\%) at $-78^{\circ} \mathrm{C}$. 
17000) and poly(PtD) $\left(M_{\mathrm{n}}(\mathrm{SEC})=20000\right)$ showed that their glass transition temperatures $\left(T_{\mathrm{g}}\right)$ were 163 and $115{ }^{\circ} \mathrm{C}$, respectively (Fig. 4A). The $T_{\mathrm{g}}$ value of poly $((-)-\mathrm{VnD})$ was the highest due to the rigid bicyclic skeleton compared to those of the other biobased polymers obtained from terpenes, including poly $\left(\beta\right.$-Pin) $\left(90^{\circ} \mathrm{C}\right)$ and its hydrogenated form (130 $\left.{ }^{\circ} \mathrm{C}\right) .{ }^{18,19}$ TGA under a nitrogen atmosphere revealed that the $5 \%$ weight loss temperatures $\left(T_{\mathrm{d} 5}\right)$ of poly $(\mathrm{VnD})$ and poly $(\mathrm{PtD})$ were 268 and $260{ }^{\circ} \mathrm{C}$, respectively, and were slightly lower than the $5 \%$ weight loss temperatures of poly $( \pm)$-HCvD) $(285$ $\left.{ }^{\circ} \mathrm{C}\right)$ and poly ( $\beta$-Phe) $\left(289^{\circ} \mathrm{C}\right)$ (Fig. 4B).

The optical activity of poly $((-)-\mathrm{VnD})$ and poly(PtD) was measured in THF at $25{ }^{\circ} \mathrm{C}$ (Table S2). Both poly $((-)-\mathrm{VnD})$ and poly $(\mathrm{PtD})$ were optically active due to the optical activity of the parent natural compounds. Poly $((-)-\mathrm{VnD})$ prepared from (-)$\operatorname{VnD}\left([\alpha]_{D}=-44^{\circ}\right)$, which was synthesized from the enantiomeric pure (-)-form of verbenone, showed a high optical rotation $\left([\alpha]_{D}=+110^{\circ}\right)$, whereas poly (PtD) prepared from

PtD

$\left([\alpha]_{D}=\right.$

$+15^{\circ}$ ),

which

was

synthesi

zed

from a

mixture

of

enantio

mers of

piperito

ne with

Fig. 5. Plausible solid catalysts.

\section{predomi}

nantly $(R)-(-)$-form, showed a low value $\left([\alpha]_{D}=-11^{\circ}\right)$. The presence of optical activity in the resulting polymers indicates that no undesirable side reactions occurred on the asymmetric carbons during the cationic polymerization and that the welldefined optically active monomer units were incorporated in the polymer chains.

\section{Hydrogenation of polymers}

Hydrogenation of polymers obtained from (-)-HCvD, PtD, and $(-)-\mathrm{VnD}$ was investigated using various solid catalysts with pressured $\mathrm{H}_{2}$ gas in $n$-hexane under various conditions (Table S3).

Although poly((-)-HCvD)) obtained by regioselective and stereospecific cationic polymerization was not soluble in common organic solvents except for $\mathrm{C}_{2} \mathrm{H}_{2} \mathrm{Cl}_{4}$ due to the crystalline-like structure, ${ }^{28}$ the polymers obtained after hydrogenation using $\mathrm{Pd} / \mathrm{Al}_{2} \mathrm{O}_{3}$ at $120^{\circ} \mathrm{C}$ were soluble in various solvents, including $n$-hexane, THF, and $\mathrm{CHCl}_{3}$ (entry 2 in Table S3). Thus, SEC analysis became possible and showed a narrow curve (Fig. S10), indicating that living cationic polymerization proceeded even under heterogeneous conditions due to the precipitation of the resulting polymer and that almost no significant degradation of the polymer chains occurred during the hydrogenation step. In addition, the ${ }^{1} \mathrm{H}$ and ${ }^{13} \mathrm{C} N M R$ spectra

showed

no

olefinic

structur

es and

were

quite

similar

to the

${ }^{1} \mathrm{H}$ and

${ }^{13} \mathrm{C}$ NMR spectra of hydrogenated poly $(( \pm)-\mathrm{HCVD})$ obtained by hydrogenation of the soluble polymer derived from the racemic monomer $(( \pm)-\mathrm{HCVD})$ (Fig. S10 and S11). ${ }^{28}$ Nearly quantitative hydrogenation (99\%) was thus achievable even for the insoluble poly((-)-HCVD)).

More interestingly, the hydrogenated poly((-)-HCvD)) showed optical activity $\left([\alpha]_{D}=-14^{\circ}\right)$ (Table S2), indicating the

Fig. 6. Differential scanning calorimetry (DSC) (A) and thermogravimetric analysis (TGA) (B) curves of poly $((-)-\mathrm{VnD})\left(M_{\mathrm{n}}=17000\right)$, poly (PtD) $\left(M_{\mathrm{n}}=20000\right)$, poly $(( \pm)-\mathrm{HCvD})\left(M_{\mathrm{n}}\right.$ 26500), and poly $(\beta-P h e)\left(M_{n}=90000\right)$
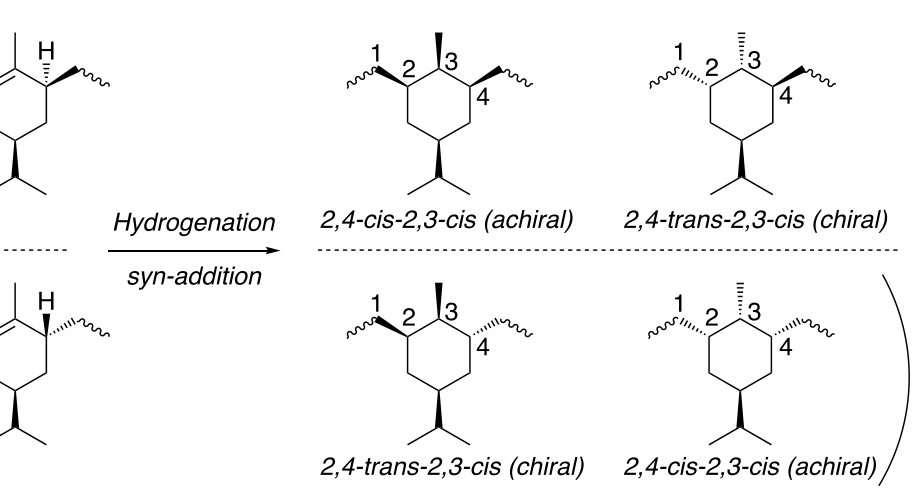

formation of biobased optically active COP. An optically active COP has been prepared by enantioselective cyclopolymerization of petroleum-derived linear unconjugated telechelic diene using a chiral metal catalyst. ${ }^{45}$ While it was obvious that the optical activity originated from the chiral monomer, i.e., (-)-HCVD, in this case, the stereostructures of the biobased COP are discussed in more detail, as follows (Fig. 5).

As reported in our previous paper, ${ }^{28}$ the chiral monomer underwent regioselective and stereospecific cationic polymerization, in which the bulky isopropyl group attached to the chiral carbon dictated the absolute configuration of the carbon at the 4-position and resulted in the stereoregular polymer. The enchainment at the 4-position most likely produced $(R)$-form, in which the mutual stereostructure between the isopropyl and main-chain methylene groups was the cis form, to eliminate the 1,3-diaxial interaction caused by the bulky isopropyl substituent. Then, the subsequent hydrogenation with solid catalysts occurred via syn-addition and could then produce two stereostructures with 2,4-cis-2,3cis and 2,4-trans-2,3-cis if the hydrogenation was not diasteroselective. Although the presence of the former stereostructure (2,4-cis-2,3-cis) is suggested by the characteristic upfield $(6.0 \mathrm{ppm})$ carbon peak, which can be assigned to the methyl carbon at the 3-position according to a 
similar methyl carbon (5.3 ppm) of the model compound 1-cis2 -cis-3-trimethylcyclohexane, ${ }^{46}$ the $2,4-c i s-2,3-c i s$ structure is not chiral due to the symmetrical structure. Therefore, the optical activity can be attributed to the chiral 2,4-trans-2,3-cis structure, in which the methyl carbon should appear at approximately $15 \mathrm{ppm}$ according to a similar methyl carbon (17.4 ppm) of the model compound 1-cis-2-trans-3trimethylcyclohexane. These results indicate that hydrogenation is not diastereoselective and produces both 2,4-cis-2,3-cis and 2,4-trans-2,3-cis structures. The same conclusion can also be derived in the event that stereospecific cationic polymerization produces the (S)-configuration. ${ }^{28}$ In addition, the ${ }^{13} \mathrm{C}$ NMR spectrum of the hydrogenated chiral polymer (Fig. S11B), which is similar to the ${ }^{13} \mathrm{C}$ NMR spectrum of the hydrogenated achiral polymer obtained from ( \pm )-HCVD (Fig. S11C), confirms that the stereoselectivity during hydrogenation could not be induced by the chiral monomer unit in the chains.

After hydrogenation, the $T_{\mathrm{g}}$ of the chiral polymer increased from 113 to $124{ }^{\circ} \mathrm{C}$ (Fig. 6A), similar to achiral poly( \pm )-HCvD). ${ }^{28}$ TGA revealed that $T_{\mathrm{d} 5}$ significantly increased from 288 to 393 ${ }^{\circ} \mathrm{C}$ due to saturation of the less stable olefinic carbons (Fig. 6B). These results indicate that a novel biobased chiral COP with good thermal properties was obtained by living cationic polymerization of the terpenoid-derived chiral exo-methyleneconjugated diene followed by hydrogenation.
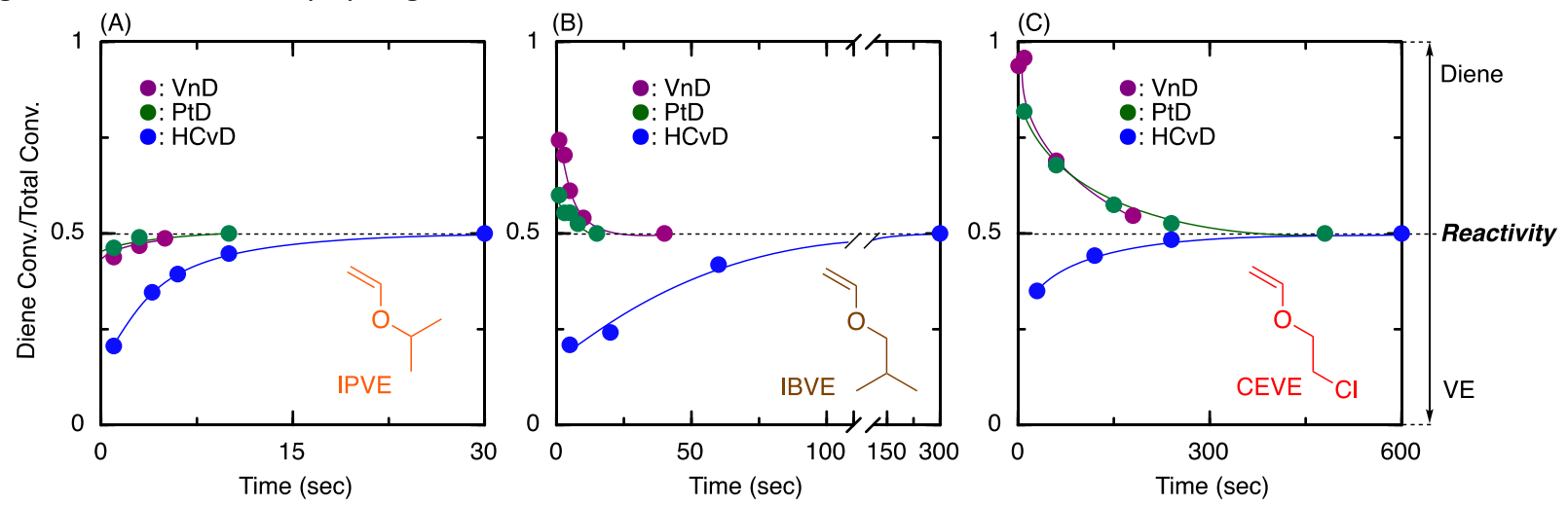

Fig. 7. Plots of diene conversion in total monomer conversion vs. time in living cationic copolymerization of exo-methylene conjugated dienes and vinyl ethers: [diene $]_{0} /[\mathrm{VE}]_{0} /[2]_{0} /\left[\mathrm{SnCl}_{4}\right]_{0} /\left[n \mathrm{Bu}_{4} \mathrm{NCl}\right]_{0}=100 / 100 / 1.0 / 5.0 / 4.0 \mathrm{mM}$ in toluene $/ \mathrm{CH}_{2} \mathrm{Cl}_{2}\left(50 / 50\right.$ vol\%) at $-78^{\circ} \mathrm{C}$.

Poly(PtD) was also completely hydrogenated using $\mathrm{Pd} / \mathrm{Al}_{2} \mathrm{O}_{3}$ in $n$-hexane at $120^{\circ} \mathrm{C}$ (entry 4 in Table S3), as clearly indicated by the disappearance of olefinic protons and carbons (Fig. S12 and S13, respectively). However, the SEC curve of the hydrogenated polymer shifted to a low molecular weight and indicated a decrease in $M_{n}(\mathrm{SEC})$ from 23200 to 7300 , suggesting that main-chain scission occurred concurrently during hydrogenation (Fig. S12C). Irrespective of the decrease in $M_{n}$, the $T_{\mathrm{g}}$ value increased slightly from 112 to $120^{\circ} \mathrm{C}$ (Fig. 6A). In addition, $T_{\mathrm{d} 5}$ increased dramatically from 260 to $343{ }^{\circ} \mathrm{C}$ due to complete hydrogenation (Fig. 6C). Among the other catalysts tested, $\mathrm{Pd} / \mathrm{CeO}_{2}$ was only moderately efficient for hydrogenation (56\%) along with a slight decrease in $M_{\mathrm{n}}$ from 23200 to 17800 (entry 7 in Table S3).

Finally, the hydrogenation of poly $((-)-V n D)$ was investigated using various catalysts under various conditions (entries 11-18 in Table S3). Although hydrogenation proceeded in several cases, significant decreases in the molecular weights were observed $\left(M_{\mathrm{n}}<1000\right)$ due to concurrent degradation of the polymer chains. The difficulty in clean hydrogenation without side reactions can be ascribed to the bulky bicyclic repeating unit of $\mathrm{VnD}$.

Nevertheless, these results indicate that unique structures originating from naturally occurring $\alpha, \beta$-unsaturated carbonyl compounds with a substituted 6-membered ring induce characteristic polymerizations in terms of reactivity and selectivity and result in novel biobased polymers in terms of stereostructures, thermal properties, and optical activities.

\section{Living cationic copolymerization of exo-methylene-conjugated dienes and vinyl ethers}

As we found that a series of exo-methylene-conjugated dienes have high reactivity in cationic homopolymerization, we then examined the cationic copolymerization of these dienes with various VEs. VE comonomers were chosen because they are among the most reactive monomers in cationic polymerization and allow us to evaluate the reactivity of the exo-methyleneconjugated dienes in more detail. Herein, isopropyl vinyl ether (IPVE), IBVE, and CEVE were chosen as the comonomers, where the order of the reactivity is as follows: IPVE > IBVE > CEVE. The 1:1 mixture of $( \pm)-H C V D, P t D$, or $(-)-V n D$ and IPVE, IBVE, or CEVE was copolymerized using the $2 / \mathrm{SnCl}_{4} / n \mathrm{Bu}_{4} \mathrm{NCl}$ initiating system under the conditions used for the living cationic homopolymerization of these dienes.

All the monomers were almost quantitatively consumed, while the relative rates were dependent on the comonomers (Fig. S14). To compare the relative consumption ratios of the comonomers more visibly, Fig. 7 plots the ratio of diene conversion over total monomer conversion against time. In this plot, the top half of the diagram (above 0.5) indicates that the monomer has higher reactivity than VE.

One of the most surprising results is that PtD and $\mathrm{VnD}$ are more reactive than not only CEVE (Fig. 7C) but also IBVE (Fig. $7 B)$, which is one of the most widely used VEs as a typical highly reactive monomer in cationic polymerization. In addition, HCVD showed reactivity similar to the reactivity of CEVE (Fig. 7C) but was less reactive than IBVE and IPVE (Fig. 7B and $7 C$, respectively). In short, the reactivity of the monomers was estimated as follows: IPVE $>$ VnD $\sim$ PtD $>$ IBVE $>$ CEVE 
HCvD: The exo-methylene-conjugated dienes, especially those bearing a methyl group at the 4-position, are thus among the most reactive monomers in cationic polymerization despite the absence of electron-donating heteroatoms such as oxygen and nitrogen attached to the vinyl group. ${ }^{44}$ Generally, a linear conjugated diene such as butadiene and isoprene possesses a much lower reactivity in cationic polymerization than VEs. Therefore, the high reactivity of the exo-methylene-conjugated dienes can be ascribed to the exo-methylene moiety in conjunction with the fixed transoid diene structure.

All the polymers obtained in the cationic copolymerization showed narrow MWDs and controlled molecular weights, indicating that the copolymerization proceeded in a living fashion because the initiating system is also effective for living cationic polymerization of VEs (Fig. S15-S17). In particular, in the HCVD/IPVE (Fig. S14A), PtD/CEVE (Fig. S14H), and VnD/CEVE (Fig. S14I) copolymerizations, one monomer (IPVE, PtD, and $V n D$ ) was consumed much faster than the other (HCVD, CEVE, and CEVE, respectively), while the $M_{\mathrm{n}}$ of the resulting polymer continued to increase linearly throughout the copolymerization, indicating the formation of tapered block copolymers (poly(IPVE-co-HCVD), poly(PtD-co-CEVE), and consumed during copolymerization, only one $T_{\mathrm{g}}$ was observed almost in the middle of the $T_{\mathrm{g}} \mathrm{s}$ of the homopolymers of the corresponding dienes and VEs. In contrast, for the tapered block copolymers, for which one monomer was consumed much faster than the other, two $T_{\mathrm{g}} \mathrm{s}$ were observed at low and high temperatures and were ascribed to the soft poly(VE) and hard poly(diene) segments, respectively, indicating microphase separation.

\section{Block copolymerization of exo-methylene-conjugated dienes and vinyl ethers}

The block copolymerization of exo-methylene-conjugated dienes and VEs was investigated to synthesize well-defined block copolymers using sequential addition of the second monomer in the living cationic polymerization with $\mathbf{1}, \mathbf{2}$, or hydrogen chloride adduct (3) of IPVE in the presence of $\mathrm{SnCl}_{4}$ and $n \mathrm{Bu}_{4} \mathrm{NCl}$ in toluene $/ \mathrm{CH}_{2} \mathrm{Cl}_{2}(1 / 1)$ at $-78{ }^{\circ} \mathrm{C}$.

For the pair of $\mathrm{HCVD}$ and IBVE or CEVE, HCVD, i.e., the least reactive monomer, was first polymerized, and then an equimolar amount of IBVE or CEVE was added when HCVD was almost consumed (Fig. 9A and 9B). In both cases, the SEC
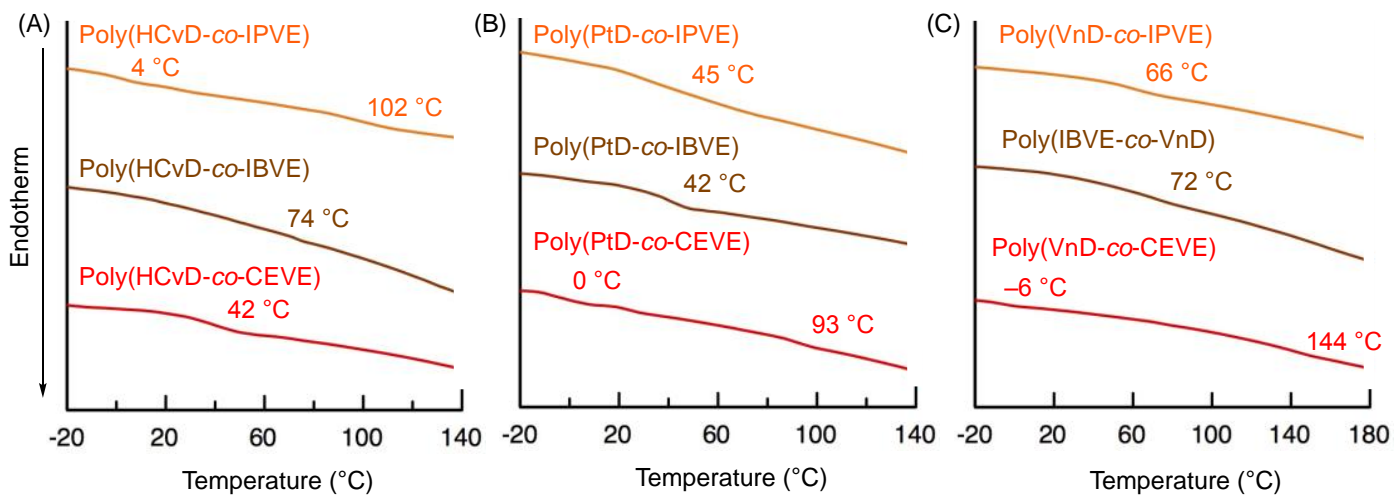

Fig. 8. DSC curves of the copolymers obtained in living cationic copolymerization of ( \pm )-HCVD (A), PtD (B), or (-)-VnD (C) with various VEs. $M_{n}=36600$ (poly(HCvD-co-IPVE)), 23500 (poly(HCVD-co-IBVE)), 27600 (poly(HCVD-co-CEVE)), 31300 (poly(PtD-co-IPVE)), 26000 (poly(PtD-co-IBVE)), 24400 (poly(PtD-co-CEVE)), 19200 (poly(VnD-co-IPVE)), 17300 (poly(VnDco-IBVE)), 17700 (poly(VnD-co-CEVE)).

poly(VnD-co-CEVE)) by living cationic copolymerization of two monomers with largely different reactivities.

The ${ }^{1} \mathrm{H}$ NMR spectra of all copolymers showed that the exo-methylene-conjugated dienes also underwent regioselective 1,4-conjugated addition even in the copolymerization and that the composition of the diene and VE units in the copolymers was close to the calculated value (Fig. S18-20). In addition, peaks of the diene units in the copolymers obtained from the monomers with similar reactivities, such as poly(VnD-co-IPVE), were broader than the peaks of the homopolymer, whereas those in the copolymers obtained from the monomers with largely different reactivities, such as poly(VnD-co-CEVE), were sharp. Thus, both statistically random and tapered block copolymers were produced according to the difference in the cationic copolymerization reactivities of the two monomers.

The DSC curves also supported the random and tapered structures of the copolymers (Fig. 8). For the random copolymers, for which both monomers were concurrently curves showed a narrow MWD and shifted to high molecular weights, indicating successful synthesis of the block copolymers. In general, for the synthesis of well-defined block copolymers by living cationic polymerization, the most reactive monomer should be polymerized first, and the least reactive monomer should be added because the dormant species derived from a more reactive monomer has a higher activity, which ensures fast and quantitative initiation for block copolymerization of the second monomer. ${ }^{44}$ The order of addition used here was opposite to this general rule but led to successful formation of the block copolymers (poly(HCVD- $b$ IBVE) and poly(HCVD- $b$-CEVE)) nonetheless.

The reverse order was also examined: IBVE or CEVE were polymerized first, and HCVD was then added (Fig. 9C and 9D). The SEC curve of poly(IBVE) showing a narrow MWD finally shifted to a high molecular weight, indicating the high blocking efficiency and the formation of poly(IBVE- $b$-HCVD). For CEVE, the main peak clearly shifted to high molecular weight, but a small portion of poly(CEVE) remained as a small shoulder peak. 
The block copolymerization of $\mathrm{VnD}$, which has the highest reactivity and results in the highest $T_{\mathrm{g}}$ with IPVE or IBVE was finally investigated (Fig. 9E and 9F). In both cases, VEs were first polymerized, and then $\mathrm{VnD}$ was added. Since the appropriate ratios of $\mathrm{SnCl}_{4} / n \mathrm{Bu}_{4} \mathrm{NCl}$ for the living cationic polymerizations of IPVE and $\mathrm{VnD}$ were different, $\mathrm{SnCl}_{4}$ was also added upon the addition of $\mathrm{VnD}$. In particular, the SEC curve of poly(IPVE) shifted completely to high molecular weights without residual homopolymer, indicating the successful formation of poly(IPVE- $b-\mathrm{VnD})$. Although a small shoulder remained in the case of poly(IBVE), the main peak clearly shifted to high molecular weights. These results indicate that block copolymers of exo-methylene-conjugated dienes and VEs were obtained by appropriate combination of monomers with adequate orders of additions.

The structure and thermal properties of the block copolymers were analyzed by ${ }^{1} \mathrm{H} N M R$, DSC, and atomic force microscopy (AFM). The ${ }^{1} \mathrm{H}$ NMR spectra (Fig. S21 and S22) of the resulting block copolymers showed basically a series of superimposed peaks of each homopolymer and sharper peaks than those of the statistical random copolymers, supporting the block structure. In addition, the incorporated ratios of each
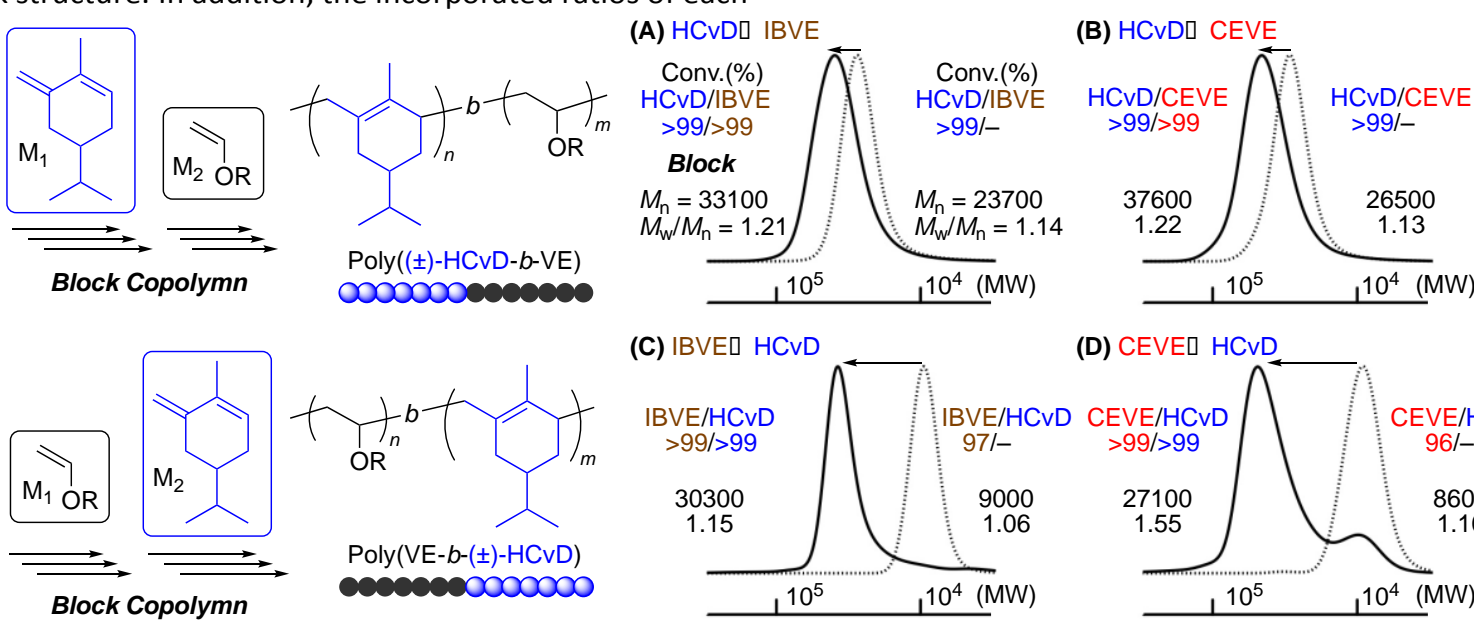

(C) IBVEQ HCVD

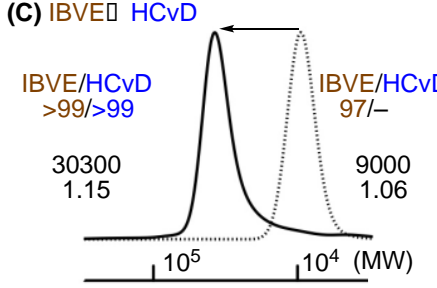

(D) CEVED HCvD
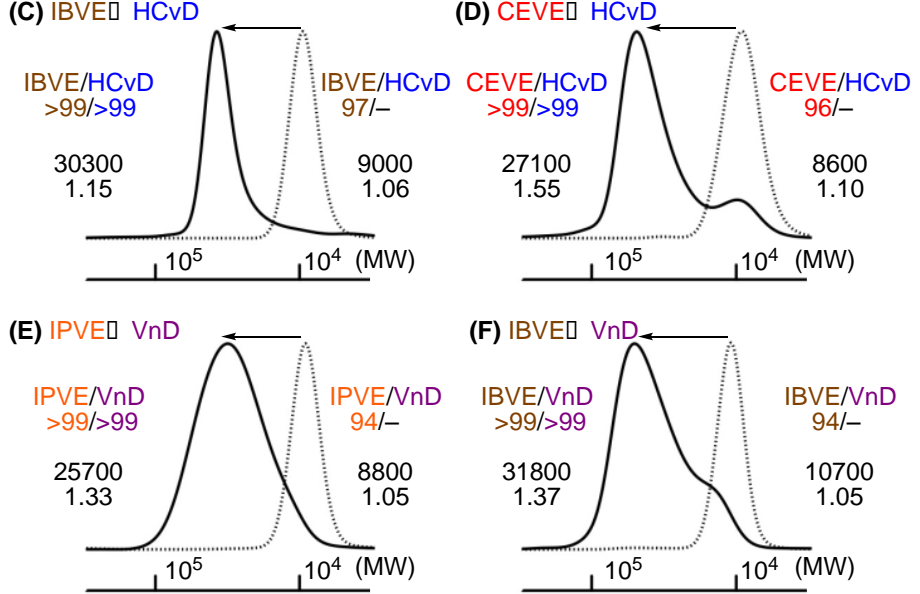

Fig. 9. SEC curves for the block copolymerization of ( \pm )- $\mathrm{HCVD}$ or $(-)-\mathrm{VnD}$ with various vinyl ethers. $\left[\mathrm{M}_{1}\right]_{0} /\left[\mathrm{M}_{2}\right]_{\text {add }} /\left[\mathrm{initiator}_{0} /\left[\mathrm{SnCl}_{4}\right]_{0} /\left[\mathrm{nB \textrm {H } _ { 4 }} / \mathrm{NCl}\right]_{0}=100 / 100 / 1.0 / 5.0 / 4.0(\mathrm{except} \mathrm{E})\right.$ $\mathrm{mM}$ in toluene/ $\mathrm{CH}_{2} \mathrm{Cl}_{2}\left(50 / 50\right.$ vol\%) at -78 o $\mathrm{C}: \mathrm{M}_{1} / \mathrm{M}_{2} /$ initiator $=\mathrm{HCVD} / \mathrm{IBVE} / \mathbf{2}$ (A), $\mathrm{HCVD} / \mathrm{CEVE} / \mathbf{1}$ (B), IBVE/HCVD/2 (C), CEVE/HCvD/2 (D), IBVE/VnD/2 (F); $[\mathrm{IPVE}]_{0} /[3]_{0} /\left[\mathrm{SnCl}_{4}\right]_{0} /\left[n \mathrm{Bu}_{4} \mathrm{NCl}\right]_{0}=100 / 1.0 / 5.0 / 7.0 \mathrm{mM},[\mathrm{VnD}]_{\text {add }} /\left[\mathrm{SnCl}_{4}\right]_{\mathrm{add}}=100 / 8.75 \mathrm{mM}(\mathrm{E})$.

monomer unit measured using the peak intensity ratios were in good agreement with the calculated values based on the monomer feed ratios and the monomer conversions. These ${ }^{1} \mathrm{H}$ NMR analysis results further indicate the formation of block copolymers.

In addition, DSC curves of the typical block copolymers showed two characteristic $T_{\mathrm{g}} \mathrm{s}$ below $0{ }^{\circ} \mathrm{C}$ and over $100{ }^{\circ} \mathrm{C}$, indicating the microphase separation of soft polar VE and hard nonpolar cycloolefin segments (Fig. 10). The combination of these segments can be applicable for a unique biobased of IPVE/VnD = 40/60) was analyzed by AFM with the spincoated thin film (average thickness $=80 \mathrm{~nm}$ ) under various conditions. The AFM image of the dried film after spin coating (Fig. 11A) showed microphase separation with a characteristic distance of approximately $30 \mathrm{~nm}$. Although no local or longrange order was observed, this observation confirmed the formation of a copolymer architecture composed of two incompatible blocks, resulting in a microphase-separated morphology. This was further revealed by an ultraviolet-ozone (UVO) treatment of the thin film that differentially removed 
the components of the block copolymer (Fig. 11B), enhancing the image contrast. This poorly ordered morphology, with segregated domains oriented randomly in the plane of the film but also within the thickness of the film, is a direct consequence of the spin-coating process, where the films generally end up in a nonequilibrium state due to the competition between phase separation kinetics and vitrification as the solvent evaporates. ${ }^{48}$ Although thermal annealing $\left(50,100,150\right.$, and $200{ }^{\circ} \mathrm{C}$ for $5 \mathrm{~min}$ ) and solvent annealing with THF vapors were applied after spin coating, almost no further improvements in regulating the morphology were observed. This specific feature, which may be related to the very rigid nonpolar $\mathrm{VnD}$ block, is now under careful investigation.

The results from ${ }^{1} \mathrm{H}$ NMR, DSC, and AFM analyses indicate the formation of block copolymers with microphase separation consisting of soft vinyl ether and hard nonpolar naturally derived exo-methylene-conjugated diene segments, which could be used as a novel biobased thermoplastic elastomer.

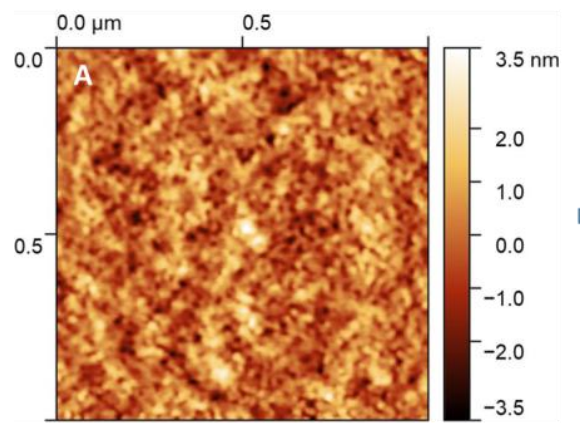

terms of reactivity in cationic polymerization as well as polymer properties for novel biobased polymeric materials.

\section{Experimental section}

\section{Materials}

Tetrahydrofuran (THF) (KANTO, >99.5\%; $\mathrm{H}_{2} \mathrm{O}<0.001 \%$ ), toluene (KANTO, >99.5\%; $\mathrm{H}_{2} \mathrm{O}<10 \mathrm{ppm}$ ), dichloromethane $\left(\mathrm{CH}_{2} \mathrm{Cl}_{2}\right.$ ) (KANTO, >99.5\%; $\mathrm{H}_{2} \mathrm{O}<0.005 \%$ ), and diethyl ether $\left(\mathrm{Et}_{2} \mathrm{O}\right)$ (KANTO, >99.5\%; $\mathrm{H}_{2} \mathrm{O}<50 \mathrm{ppm}$ ) were dried and deoxygenized by passage through Glass Contour Solvent Systems columns before use. Piperitone (mixture of enantiomers, predominantly $(R)$-form, Tokyo Chemical Industry, >94\%), (-)-carvone (Tokyo Chemical Industry, >99\%), (+)-carvone (Tokyo Chemical Industry, >98\%), angelica seed oil (Aldrich, containing approximately 80\% $\beta$-phellandrene), 1,2,3,4-tetrahydronaphthalene (Wako, 97\%), 2-chloroethyl vinyl ether (CEVE) (Tokyo Chemical Industry, >97\%), isobutyl

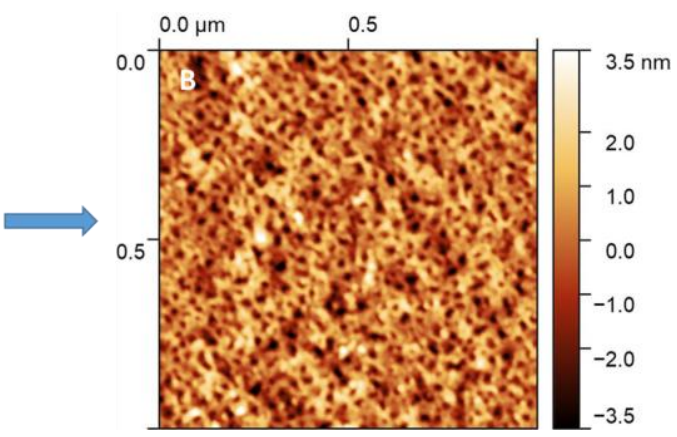

Fig. 11. Tapping mode AFM images of the poly(IPVE- $b-V n D)$ film (A) after spin coating and (B) after UVO exposure for 5 min.

\section{Conclusions}

A series of biobased exo-methylene-conjugated dienes with a substituted 6-membered ring were prepared from naturally occurring $\alpha, \beta$-unsaturated carbonyl compounds and polymerized with initiating systems effective for living cationic polymerization of vinyl ethers. These dienes possess high cationic polymerizability comparable to alkyl vinyl ethers and successfully undergo living cationic polymerization via a selective 1,4-conjugated addition to be converted into welldefined novel biobased polymers bearing characteristic substituted cyclohexenyl rings. The reactivity of the monomer and thermal properties of the resulting polymer are dependent on the substituents. In particular, $(-)-\mathrm{VnD}$, which has a methyl group at the 4-position and a fused 4- and 6membered ring, possesses the highest reactivity and results in the polymer with the highest $T_{\mathrm{g}}\left(\sim 160{ }^{\circ} \mathrm{C}\right)$. These conjugated dienes are copolymerized with various vinyl ethers in a living fashion to result in statistically random or tapered block copolymers depending on the reactivities of the comonomers. The block copolymers of vinyl ethers and exo-methyleneconjugated dienes prepared using a sequential monomer addition method possess two glass transition temperatures below $0{ }^{\circ} \mathrm{C}$ and above $100{ }^{\circ} \mathrm{C}$ due to the microphase-separated morphology. Thus, exo-methylene-conjugated dienes derived from naturally occurring terpenoids are unique monomers in vinyl ether (IBVE) (Tokyo Chemical Industry, >99\%), and isopropyl vinyl ether (IPVE) (Wako, 97\%) were distilled under reduced pressure before use. (-)-Verbenone (Tokyo Chemical Industry, $>95 \%$ ) was purified by column chromatography on silica gel with $n$-hexane/ethyl acetate $(6 / 4)$ as the eluent to result in the pure compound $\left(>99 \%\right.$ ). $\mathrm{Pd} / \mathrm{Al}_{2} \mathrm{O}_{3}$ (Tokyo Chemical Industry, 5 wt\%), $\mathrm{Pt} / \mathrm{Al}_{2} \mathrm{O}_{3}$ (Engelhard Corporation, 20 wt\%), $\mathrm{Pd} / \mathrm{C}$ (Engelhard Corporation, $5 \mathrm{wt} \%$ ), $\mathrm{PtO}_{2}$ (Tokyo Chemical Industry, >85\%), (methyl)triphenylphosphonium bromide (KANTO, >98\%), potassium tert-butoxide (Tokyo Chemical Industry, >97\%), $\mathrm{SnCl}_{4}$ (Aldrich, $1.0 \mathrm{M}$ solution in $\mathrm{CH}_{2} \mathrm{Cl}_{2}$ ), $\mathrm{ZnCl}_{2}$ (Aldrich, $1.0 \mathrm{M}$ solution in $\mathrm{Et}_{2} \mathrm{O}$ ), $\mathrm{EtAlCl}_{2}$ (KANTO, $1.0 \mathrm{M}$ solution in $n$-hexane), $\mathrm{BF}_{3} \cdot \mathrm{OEt}_{2}$ (Aldrich), $\mathrm{TiCl}_{4}$ (Aldrich), tetrabutylammonium chloride $\left(n \mathrm{Bu}_{4} \mathrm{NCl}\right)$ (Tokyo Chemical Industry, >98\%), and ethanol (KANTO, >99.5\%) were used as received. The hydrogen chloride adducts of CEVE (1), IBVE (2), and IPVE (3) were synthesized by bubbling dry $\mathrm{HCl}$ gas into a 1.0 $\mathrm{M}$ solution of CEVE in hexane at $-78{ }^{\circ} \mathrm{C}$, and then dry nitrogen was bubbled to remove excess $\mathrm{HCl}$ as reported. ${ }^{47}(-)$ $\mathrm{VnD}, \mathrm{PtD},(-)-$ and $(+)-\mathrm{HCVD}$, and $\beta$-Phe were prepared according to the literature. ${ }^{28,41} \mathrm{Pd} / \mathrm{CeO}_{2}$ (Pd: $5 \mathrm{wt} \%$ ), $\mathrm{Pd} / \mathrm{SiO}_{2}$ (Pd: 1 wt\%), Pt/CeO 2 (Pt: 5 wt\%), and $\mathrm{Pt} / \mathrm{SiO}_{2}$ (Pt: 2 wt\%) were prepared by impregnation method: The support $\left(\mathrm{SiO}_{2}\right.$ (Fuji Silysia Chemical Ltd., G-6) or $\mathrm{CeO}_{2}$ (Daiichi Kigenso Kagaku Kogyo Co., Ltd., $\left.\mathrm{CeO}_{2}-\mathrm{HS}\right)$ ) was impregnated with the $\mathrm{Pt}\left(\mathrm{NH}_{3}\right)_{4} \cdot\left(\mathrm{NO}_{3}\right)_{2}$ aq (Aldrich) or $\mathrm{Pd}\left(\mathrm{NO}_{3}\right)_{2}$ aq (N.E. CHEMCAT Corporation) by heating with a hot plate at $353 \mathrm{~K}$, and after 
drying the obtained wet catalyst at $383 \mathrm{~K}$ for $12 \mathrm{~h}$, the dried catalysts were obtained. The dried $\mathrm{Pd} / \mathrm{SiO}_{2}$ and $\mathrm{Pt} / \mathrm{SiO}_{2}$ were calcined at $773 \mathrm{~K}$ and $673 \mathrm{~K}$ under air for $3 \mathrm{~h}$, respectively, the dried $\mathrm{Pd} / \mathrm{CeO}_{2}$ and $\mathrm{Pt} / \mathrm{CeO}_{2}$ were annealed under $\mathrm{N}_{2}$ at $573 \mathrm{~K}$ for $1 \mathrm{~h}$, and the desired catalysts were obtained.

\section{Living Cationic Polymerization}

The living cationic polymerizations were carried out by a syringe technique under dry nitrogen in baked glass tubes equipped with a three-way stopcock. A typical example of the polymerization of $(-)-\mathrm{VnD}$ with $2 / \mathrm{SnCl}_{4} / \mathrm{nBu}_{4} \mathrm{NCl}$ is given below. The reaction was initiated by the sequential addition of 2 (10 mM in toluene; $0.60 \mathrm{~mL}$ ) and a mixture of $\mathrm{SnCl}_{4}$ and $n \mathrm{Bu}_{4} \mathrm{NCl}\left(50 \mathrm{mM} \mathrm{SnCl}_{4}\right.$ and $40 \mathrm{mMnBu} \mathrm{NCl}_{4}$ in $\mathrm{CH}_{2} \mathrm{Cl}_{2} ; 0.60 \mathrm{~mL}$ ) via a dry syringe into the monomer solution $(4.8 \mathrm{~mL})$ containing (-)-VnD (0.089 $\mathrm{g}, 0.60 \mathrm{mmol})$ and $1,2,3,4$ tetrahydronaphthalene $(0.04 \mathrm{~mL})$ in toluene and $\mathrm{CH}_{2} \mathrm{Cl}_{2}(1 / 1)$ at $-78^{\circ} \mathrm{C}$. The total volume of the reaction mixture was $6.0 \mathrm{~mL}$. At predetermined intervals, the polymerization was terminated with methanol $(1.0 \mathrm{~mL})$ containing a small amount of ammonia. Monomer conversion was determined from the concentration of the residual monomer as measured by ${ }^{1} \mathrm{H}$ NMR with 1,2,3,4-tetrahydronaphthalene as an internal standard $(89 \%$ in $1 \mathrm{sec})$. The quenched reaction mixture was diluted with hexane and then washed with aqueous $\mathrm{HCl}$ and water. The organic layer was concentrated to dryness under reduced pressure and vacuum-dried to give the product polymer $\left(M_{\mathrm{n}}=14000, M_{\mathrm{w}} / M_{\mathrm{n}}=1.13\right)$.

\section{Living Cationic Copolymerization}

The living cationic copolymerizations were carried out by a syringe technique under dry nitrogen in baked glass tubes equipped with a three-way stopcock. A typical example of the copolymerization of (-)- $\mathrm{VnD}$ and IBVE with $2 / \mathrm{SnCl}_{4} / n \mathrm{Bu}_{4} \mathrm{NCl}$ is given below. The reaction was initiated by the sequential addition of 2 (10 mM in toluene; $0.60 \mathrm{~mL}$ ) and a mixture of $\mathrm{SnCl}_{4}$ and $n \mathrm{Bu}_{4} \mathrm{NCl}\left(50 \mathrm{mM} \mathrm{SnCl}_{4}\right.$ and $40 \mathrm{mMnBu} \mathrm{NCl}_{4} \mathrm{CH}_{2} \mathrm{Cl}_{2}$; $0.60 \mathrm{~mL}$ ) via a dry syringe into the monomer solution $(4.8 \mathrm{~mL})$ containing a $1: 1$ mixture of $(-)-\mathrm{VnD}(0.089 \mathrm{~g}, 0.60 \mathrm{mmol})$ and IBVE (0.060 g, $0.60 \mathrm{mmol})$ and 1,2,3,4-tetrahydronaphthalene $(0.04 \mathrm{~mL})$ in toluene and $\mathrm{CH}_{2} \mathrm{Cl}_{2}(1 / 1)$ at $-78{ }^{\circ} \mathrm{C}$. The total volume of the reaction mixture was $6.0 \mathrm{~mL}$. At predetermined intervals, the polymerization was terminated with methanol $(1.0 \mathrm{~mL})$ containing a small amount of ammonia. Monomer conversion was determined from the concentration of the residual monomer as measured by ${ }^{1} \mathrm{H}$ NMR with $1,2,3,4-$ tetrahydronaphthalene as an internal standard (VnD: $84 \%$ and IBVE: $29 \%$ in $1 \mathrm{sec}$ ). The quenched reaction mixture was diluted with hexane and then washed with aqueous $\mathrm{HCl}$ and water. The organic layer was concentrated to dryness under reduced pressure and vacuum-dried to give the product polymer $\left(M_{\mathrm{n}}=12300, M_{\mathrm{w}} / M_{\mathrm{n}}=1.23\right)$.

\section{Living Cationic Block Copolymerization}

The living cationic block copolymerizations were carried out by a syringe technique under dry nitrogen in baked glass tubes equipped with a three-way stopcock. The synthesis of the
poly(IPVE-block-(-)-VnD) block copolymer is given below. The living cationic polymerization of IPVE was first initiated by the sequential addition of $3(10 \mathrm{mM}$ in toluene; $0.60 \mathrm{~mL})$ and a mixture of $\mathrm{SnCl}_{4}$ and $n \mathrm{Bu}_{4} \mathrm{NCl}\left(50 \mathrm{mM} \mathrm{SnCl}_{4}\right.$ and $70 \mathrm{mM}$ $n \mathrm{Bu}_{4} \mathrm{NCl}$ in $\mathrm{CH}_{2} \mathrm{Cl}_{2} ; 0.60 \mathrm{~mL}$ ) via a dry syringe into the monomer solution $(4.8 \mathrm{~mL})$ containing IPVE $(0.052 \mathrm{~g}, 0.60 \mathrm{mmol})$ and 1,2,3,4-tetrahydronaphthalene $(0.03 \mathrm{~mL})$ in toluene and $\mathrm{CH}_{2} \mathrm{Cl}_{2}$ $(1 / 1)$ at $-78{ }^{\circ} \mathrm{C}$. The total volume of the reaction mixture was $6.0 \mathrm{~mL}$. After $40 \mathrm{sec}$ (the conversion of IPVE $=94 \%, M_{\mathrm{n}}=8800$, $\left.M_{\mathrm{w}} / M_{\mathrm{n}}=1.05\right)$, the monomer solution $(0.21 \mathrm{~mL})$ containing $\operatorname{VnD}(0.089 \mathrm{~g}, 0.60 \mathrm{mmol}$ in toluene) was added into the reaction solution, and then the solution of $\mathrm{SnCl}_{4}(225 \mathrm{mM}$ in $\mathrm{CH}_{2} \mathrm{Cl}_{2} ; 0.10 \mathrm{~mL}$ ) was added. After $30 \mathrm{~min}$, the polymerization was terminated by the addition of methanol $(1 \mathrm{~mL})$ containing a small amount of ammonia. Monomer conversion was determined from the concentration of the residual monomer as measured by ${ }^{1} \mathrm{H}$ NMR (IPVE $=>99 \%$ and $\mathrm{VnD}$ : $>99 \%$ ). The quenched reaction mixture was diluted with toluene and then washed with aqueous $\mathrm{HCl}$ and water. The organic layer was concentrated to dryness under reduced pressure and vacuumdried to give the product block copolymer $\left(M_{\mathrm{n}}=25700, M_{\mathrm{w}} / M_{\mathrm{n}}\right.$ $=1.33$ ).

\section{Hydrogenation of polymers}

A typical example of the hydrogenation of poly((-)-HCvD)) is given below.Poly ((-)-HCvD) (300 mg), $\mathrm{Pd} / \mathrm{Al}_{2} \mathrm{O}_{3}$ catalyst (151 $\mathrm{mg}, 5 \mathrm{wt} \%$ on $\left.\mathrm{Al}_{2} \mathrm{O}_{3}\right)$, and $n$-hexane $(6.52 \mathrm{~g}, 9.89 \mathrm{~mL}$ ) were placed in a glass inner vessel, and the glass vessel was inserted into a $190 \mathrm{~mL}$ autoclave reactor under air at room temperature. After sealing the reactor, the air in the autoclave was purged by flushing with $\mathrm{H}_{2}$ (1 MPa, 99.99\%, Nippon Peroxide Co., Ltd.) three times, and the autoclave was pressured to $5 \mathrm{MPa}$ by $\mathrm{H}_{2}$ at room temperature. The suspension mixture was heated to $120{ }^{\circ} \mathrm{C}$ and vigorously stirred at $6.5 \mathrm{MPa}_{2}$ for $3 \mathrm{~h}$. After the reaction, the reactor was cooled to room temperature in a water bath, and then the catalyst was removed by filtration. The $n$-hexane solvent was removed from the reaction mixture by evaporation to give hydrogenated poly((-)-HCVD)) (58 $\mathrm{mg})$ (degree of hydrogenation $\geq 99 \%$ ).

\section{Measurements}

${ }^{1} \mathrm{H}$ and ${ }^{13} \mathrm{C}$ NMR spectra were recorded in a JEOL ECS-400 spectrometer operating at 400 and $100 \mathrm{MHz}$, respectively. The number-average molecular weight $\left(M_{n}\right)$ and molecular weight distribution $\left(M_{\mathrm{w}} / M_{\mathrm{n}}\right)$ of the product polymer were determined by SEC in THF at $40{ }^{\circ} \mathrm{C}$ on two polystyrene gel columns [Tosoh Multipore $\mathrm{H}_{\mathrm{xL}}-\mathrm{M}(7.8 \mathrm{~mm}$ i.d. $\times 30 \mathrm{~cm}) \times 2$; flow rate: 1.0 $\mathrm{mL} / \mathrm{min}$ ] connected to a JASCO PU-2080 precision pump and a JASCO RI-2031 detector. The columns were calibrated with standard polystyrene samples (Agilent Technologies; $M_{\mathrm{p}}=580$ 3242000, $\left.M_{\mathrm{w}} / M_{\mathrm{n}}=1.02-1.23\right)$. The glass transition temperature $\left(T_{\mathrm{g}}\right)$ of the polymers was recorded on a Q200 differential scanning calorimeter (TA Instruments Inc.). Samples were first heated to $200{ }^{\circ} \mathrm{C}$ at $10{ }^{\circ} \mathrm{C} / \mathrm{min}$, equilibrated at this temperature for $10 \mathrm{~min}$, and cooled to $0{ }^{\circ} \mathrm{C}$ at $5{ }^{\circ} \mathrm{C} / \mathrm{min}$. After being held at this temperature for $5 \mathrm{~min}$, the samples 
were then reheated to $280^{\circ} \mathrm{C}$ at $10^{\circ} \mathrm{C} / \mathrm{min}$. All $T_{\mathrm{g}}$ values were obtained from the second scan after removing the thermal history. Thermogravimetric analysis (TGA) was performed on a Q500 system (TA Instruments Inc.) at $5{ }^{\circ} \mathrm{C} / \mathrm{min}$ under nitrogen gas flow. Optical rotation was measured in a $10-\mathrm{cm}$ quartz cell on a JASCO P-2300 polarimeter. AFM in tapping mode was carried out in air with an AFM Dimension Icon model and silicon cantilevers RTESP300 from Bruker. All the displayed AFM images are height images processed with Gwyddion. For image contrast enhancement, UVO Cleaner by Jelight was used. The sample was exposed to UVO for $5 \mathrm{~min}$ (the distance between the UV lamp and sample was $5 \mathrm{~cm}$ ) and then rinsed in distilled water.

\section{Conflicts of interest}

There are no conflicts of interest to declare.

\section{Acknowledgements}

This work was supported by JSPS KAKENHI Grant Number JP2OH04809 in Hybrid Catalysis for Enabling Molecular Synthesis on Demand, Japan-France Research Cooperative Program between JSPS and CNRS (Grant number JPJSBP120192907), a project (JPNP18016) commissioned by the New Energy and Industrial Technology Development Organization (NEDO), and the Program for Leading Graduate Schools "Integrative Graduate School and Research Program in Green Natural Sciences".

\section{Notes and references}

1 J. D. Connolly and R. A. Hill, Dictionary of terpenoids, Chapman \& Hall, London, 1991.

2 R. Breitmaier, Terpenes: flavors, fragrances, pharmaca, pheromones, Wiley-VCH, Weinheim, 2006.

3 Handbook of essential oils: science, technology, and applications, ed. K. H. C. Başer and G. Buchbouer, CRC Press, Boca Baton, 2016.

4 W. F. Erman, Chemistry of the monoterpenes: an encyclopedia handbook, Marcel Dekker, Inc, New York, 1985.

5 K. Yao and C. Tang, Macromolecules, 2013, 46, 1689-1712.

6 T. Iwata, Angew. Chem. Int. Ed., 2015, 54, 3210-3215.

7 Y. Zhu, C. Romain and C. K. Williams, Nature, 2016, 540, 354-362.

8 V. Froidevaux, C. Negrell, S. Caillol, J.-P. Pascault and B. Boutevin, Chem. Rev., 2016, 116, 14181-14224.

9 A. Llevot, P.-K. Dannecker, M. von Czapiewski, L. C. Over, Z. Söyer and M. A. R. Meier, Chem. Eur. J., 2016, 22, 11510-11521.

10 M. R. Thomsett, T. E. Storr, Q. R. Monaghan, R. A. Stockman and S. M. Howdle, Green Mater., 2016, 4, 115-134.

11 A. Llevot, E. Grau, S. Carlotti, S. Grelier and H. Cramail, Macromol. Rapid Commun., 2016, 37, 9-28.

12 D. K. Schneiderman and M. A. Hillmyer, Macromolecules, 2017, 50, 3733-3749.

13 H. T. H. Nguyen, P. Rostagno, M. Qi, A. Feteha and S. A. Miller, J. Mater. Chem. A, 2018, 6, 9298-9331.

14 K. Satoh and M. Kamigaito, New polymerization methods for biobased polymers, In Bio-based polymers, ed. Y. Kimura, CMC, Tokyo, 2013, pp 95-111.
15 M. Kamigaito and K. Satoh, Bio-based hydrocarbon polymers, In Encyclopedia of polymeric nanomaterials, ed. K. Kobayashi and K. Müllen, K, Springer, Heidelberg, 2015, Vol. 1, pp 109-118.

16 M. Kamigaito and K. Satoh, Sustainable vinyl polymers via controlled polymerization of terpenes, In Sustainable polymers from biomass, ed. C. Tang and C. Y. Ryu, WileyVCH, Weinheim, 2017, pp 55-90.

17 K. Satoh, Polym. J., 2015, 47, 527-536.

18 K. Satoh, H. Sugiyama and M. Kamigaito, M. Green Chem., 2006, 8, 878-882.

19 K. Satoh, A. Nakahara, K. Mukunoki, H. Sugiyama, H. Saito and M. Kamigaito, Polym. Chem., 2014, 5, 3222-3230.

20 K. Satoh, M. Matsuda, K. Nagai and M. Kamigaito, J. Am. Chem. Soc., 2010, 132, 10003-10005.

21 M. Matsuda, K. Satoh and M. Kamigaito, Macromolecules, 2013, 46, 5473-5482.

22 M. Matsuda, K. Satoh and M. Kamigaito, KGK Kaut. Gummi Kunstst., 2013, 66 (5), 51-56.

23 M. Matsuda, K. Satoh and M. Kamigaito, J. Polym. Sci., Part A: Polym. Chem., 2013, 51, 1774-1785.

24 H. Miyaji, K. Satoh and M. Kamigaito, Angew. Chem. Int. Ed., 2016, 55, 1372-1376.

25 M. Ojika, K. Satoh and M. Kamigaito, Angew. Chem. Int. Ed., 2017, 56, 1789-1793.

26 H. Hashimoto, H. Takeshima, T. Nagai, M. Uchiyama, K. Satoh and M. Kamigaito, Polym. Degrad. Stab., 2019, 161, 183-190.

27 M. Kamigaito, K. Satoh, S. Suzuki, Y. Kori, Y. Eguchi, K. Iwasa and H. Shiroto, WO 2015/060310 A1, filed Oct. 21, 2014 and issued Apr. 30, 2015.

28 T. Nishida, K. Satoh, S. Nagano, T. Seki, M. Tamura, Y. Li, K. Tomishige and M. Kamigaito, ACS Macro Lett., 2020, 9, 1178-1183.

29 S. Kobayashi, C. Lu, T. R. Hoye and M. A. Hillmyer, J. Am. Chem. Soc., 2009, 131, 7960-7961.

30 G. Pintore, M. Usai, P. Bardesi, C. Jiliano, C. Boatto, F. Tomi, M. Chessa, R. Cerri and J. Casanova, Flavor Fragr. J., 2012, 17, 15-19.

31 D. V. Banthorpe and D. Whittaker, Chem. Rev., 1966, 66, 643-656.

32 M. Lajunen and A. M. P. Koskinen, Tetrahdron Lett., 1994, 35, 4461-4464.

33 B. A. Allal, L. E. Firdoussi, S. Allaoud, A. Karim, Y. Castanet and A. Mortreux, J. Mol. Catal. A: Chem., 2003, 200, 177184.

34 M. Rauchdi, M. A. Ali, A. Roucoux and A. Denicourt-Nowicki, Appl. Catal. A: Gen., 2018, 550, 266-273.

35 P. K. Bhattacharyya, B. R. Prema, B. D. Kulkarni and S. K. Pradhan, Nature, 1960, 187, 689-690

36 K. A. C. Vespermann, B. N. Paulino, M. C. S. Barcelos, M. G. Pessôa, G. M. Patonre and G. Molina, G. Appl. Microbiol. Biotechnol., 2017, 101, 1805-1817.

37 M. Gilles, J. Zhao, M. An and S. Agboola, Food Chem., 2010, 119, 731-737.

38 I. Telci, I. Demirtas, E. Bayram. O. Arabaci and O. Kacar, Ind. Crop. Prod., 2010, 32, 588-592.

39 K. B. Wiberg and S. D. Nielsen, J. Org. Chem., 1964, 29, 33533361.

40 R. H. Reitsema, J. Am. Pharm. Assoc., 1958, 47, 267-269.

41 T. Nishida, K. Satoh and M. Kamigaito, Molecules, 2020, 25, 5890.

42 A. Matsumoto and D. Yamamoto, J. Polym. Chem. Part A: Polym. Chem., 2016, 54, 3616-3625.

43 M. Kamigaito, Y. Maeda, M. Sawamoto and T. Higashimura, Macromolecules, 1993, 26, 1643-1649.

44 S. Aoshima and S. Kanaoka, Chem. Rev., 2009, 109, 52455287.

45 G. W. Coates and R. M. Waymouth, J. Am. Chem. Soc., 1991, 113, 6270-6271. 
46 D. K. Dalling and D. M. Grant, J. Am. Chem. Soc., 1972, 94, 5318-5324.

$47 \mathrm{H}$. Katayama, M. Kamigaito, M. Sawamoto and T. Higashimura, Macromolecules, 1995, 28, 3747-3755.

48 C. Sinturel, M. Vayer, M. Morris and M. Hillmyer, Macromolecules, 2013, 14, 5399-5415. 